$\xi=$ 줄

\title{
Dermatoglyphics: A prediction tool for dental caries
}

\author{
Smitha S. Shetty ${ }^{1 *}$, Abigail Renee Johnli ${ }^{2}$, Siti Nabila Adilah Binti Md Nor ${ }^{2}$, Amirah Binti Haron², Nur Fatihah \\ Binti Mohd ${ }^{2}$, Lavinia Gunasegaram², Muhammad Nur Taufiq Bin Mustafa ${ }^{2}$, \\ Nor Hafizah Ain Binti Mohd Zakaria ${ }^{2}$ \\ ${ }^{I}$ Department of Oral Pathology, Faculty of Dentistry, Melaka Manipal Medical College, Manipal, Karnataka, India \\ ${ }^{2}$ Undergraduate Student, Faculty of Dentistry, Melaka Manipal Medical College, Manipal, Karnataka, India \\ *Corresponding author E-mail: drsmithashetty@yahoo.co.in
}

\begin{abstract}
Background: Dermatoglyphics has been used as a powerful tool in diagnosis of physiological, medical or genetic conditions. Hence its role in predicting the dental caries which is a multifactorial disease with genetic influence has to be investigated.

Objective: The present study was conducted to investigate the role of dermatoglyphics in predicting the susceptibility of individuals to develop dental caries.

Material and methods: The study included 200 students of MMMC Manipal. Dental caries pattern was recorded using the DMFT index. The impression of thumb ridge pattern was recorded using duplicating inkpads.

Results: The male subjects showed maximum of loop pattern with $53.6 \%$ and $71 \%$ in right and left thumb respectively. The female subjects also showed the maximum of loop pattern with $54.2 \%$ both in right and left thumb. Subjects who had arch type of pattern on right thumb $(66.7 \%)$ and left thumb $(57.1 \%)$ were found to be caries free compared to loop and whorl pattern. Subjects with whorl pattern on the left thumb (34.2\%) and right (34.9\%) had DMFT > 3 compared to loop and arch.

Conclusion: Dermatoglyphics serve to strengthen the diagnostic impression of the disease from an early age and hence preventive oral health measures can be considered.
\end{abstract}

Keywords: Caries; Dental; Fingerprints; Genetics

\section{Introduction}

For decades, features of the hands have fascinated scholars, theologians, doctors and laymen alike (Abhilash et al. 2012). In today's modern world, the study of hand or simply known as dermatoglyphics is far removed from the popular image of traditional palmist uttering mysterious incantation in arcane language (Prabhu $\mathrm{N}$ et al. 2014). Instead through various scientific researches, the hands or more specifically its patterns have been recognized as a powerful tool in diagnosis of physiological, medical or genetic conditions, also in analysis of one's potential, personality and preferences (Abhilash et al. 2012).

Dermatoglyphics originates from the Greek words, 'derma' means skin and 'glyphae' means carve. Dr. Harold Cummins coined the term "dermatoglyphics"in 1926 (Patil et al. 2014). Each fingerprint is unique. Even an individual right hand and left hand fingerprint will not be the same. Even though the size increases as we age from childhood to adulthood, the pattern will not change unless it is severely injured. Fingerprints will begin to show again along with healing of the wound when there is no damage to the dermis. Dermatoglyphics is therefore considered a stable marker that once formed remains same throughout a person life ( $\mathrm{J} \& \mathrm{R}$ 2014).

In the nineteenth century, Sir Francis Galton put forth a rule called 'proof of no change', which states that an individual's dermatoglyphics remain unchanged throughout his/her lifetime. He was the first to propose that there is a relationship between human prints and genome (E et al. 2013). Dermatoglyphics is also con- sidered as a genetic marker for dental caries. The basis for considering this is due to the development of teeth, which coincides with development of epidermal ridges or finger print ridges. Both the tooth and the epidermal ridges formation begins and ends at about same time. The dermal ridges of the hand take their origin from the fetal volar pads which appear in the 6 th- $7^{\text {th }}$ week of embryonic life, at the same time as that of tooth formation in intra-embryonic life. The ridge patterns are completed by 12 th- 14 th week of gestation, i.e. at the same time as that of tooth formation completion in the embryonic life. Aside from that, the epithelium of finger buds as well as enamel has the same ectodermal origin. (Sharma \& Somani 2009, Thakkar et al. 2014).

Dermatoglyphics has been a useful tool in understanding basic questions in biology, medicine, genetics and evolution in addition to being the best and most widely used method for personal identification (Prabhu N et al. 2014). Some may not view dermatoglyphics as an independent field of study even though it has a body of theory, methods and application. However, in biology, anthropology, genetics and medicine, dermatoglyphics serves as a tool to describe, compare and contrast and at times predict occurrences and risks for biomedical events (Ramani et al. 2011). In the field of dentistry, dermatoglyphics acts as indicator for periodontitis, dental caries, certain types of dental anomalies such as cleft lip and palate, dental fluorosis and malocclusion.(E et al. 2013).

However, the relation between dental conditions and dermatoglyphic pattern is still in the infancy stage. But with increasing interest in the last decades, dermatoglyphics is seen as the window of congenital abnormalities. Early detection can anticipate clinician and initiate preventive and protective health measures at a 
very young age (Prabhu N et al. 2014a). Thus, a study to investigate the role of dermatoglyphics in predicting the susceptibility of an individual to develop dental caries was undertaken. Hence the aim of our study was to evaluate an association if any, between the type of thumb ridge pattern and dental caries incidence among the students in our institution. Also to assess if any difference exists between the right and left type of thumb ridge pattern with dental caries occurrence.

\section{Materials and methods}

A cross sectional study was performed on total of 200 dental and medical students between the age group of 19- 22 years, from Melaka Manipal Medical College, Manipal. The dental caries pattern was recorded using the DMFT index. The impression of thumb ridge pattern of the students was recorded using duplicating inkpads. Each of the student were designated a sample number which is written against individual's DMFT index and thumb impression. Informed consent was obtained from the students prior to the participation in the study. The Manipal University Ethical committee approval was obtained prior to the conduct of the study.

Recording of caries index was done using the Decayed Missing Filled Tooth (DMFT) index introduced by Henry T. Klein, Carrole F. Palmer and Knutson J. W in 1938 and modified by WHO (Soben Peter, 2009) The oral examination was done using the basic diagnostic instruments using natural light. Recording of thumb prints was done by pressing the thumb on the duplicating inkpad with slight pressure, then the thumb was placed on the sheet and impression was taken of both right and left thumb. The obtained thumb prints were then checked for the various patterns like Loop, Whorl and Arch using a 4x magnifying glass. The data obtained was subjected to statistical analysis using Chi-square test, SPSS (version 16.0) software. The criterion for statistical significance was $\mathrm{p}<0.05$.

\section{Results}

A total of 200 dental and medical students were included in our study, which included 69 males $(34.5 \%)$ and 131 females $(65.5 \%)$ students. Subjects were within the age group of 19-24 years. The subjects were divided into three groups: A (DMFT=0), B $(\mathrm{DMFT}=1-3)$ and $\mathrm{C}(\mathrm{DMFT}>3)$. The male subjects showed the maximum of loop pattern with $53.6 \%$ (Table 1) and $71 \%$ (Table 2 ) in right and left thumb respectively. The female subjects also showed the maximum of loop pattern with $54.2 \%$ (Table $1 \& 2$ ) in both right and left thumb. Arch pattern was least observed with $4.6 \%$ (Table 1) and 5.3\% [Table 2] in right and left thumb of female subjects; however the male subjects showed no arch pattern. (Table $1 \& 2$ ).

When the caries incidence was compared between male and female subjects, $21.7 \%$ of male and $17.6 \%$ of female subjects showed no caries. $23.2 \%$ of male and $35.9 \%$ of female subjects showed the maximum caries with DMFT $>3$. (Table 3 ).

Table 4 shows statistical significant association between the dermatoglyphic patterns in both right and left thumb and DMFT score. Subjects who had arch pattern on right thumb (66.7\%) and left thumb $(57.1 \%)$ were found to be caries free compared to loop and whorl pattern. Subjects with whorl pattern on the right thumb (34.9\%) and left thumb (34.2\%) had DMFT >3 compared to loop and arch pattern.

\section{Discussion}

A proper understanding of dermatoglyphics and dental structures in man can only be obtained "with knowledge on their phylogenetic and ontogenetic histories". It is known that any factor active during the time period of genetic expression is bound to affect all structures developing at that time (Agravat et al. 2014). The wide- spread interest in epidermal ridges developed only in the last several decades, when it became apparent that many patients with chromosomal aberrations had unusual ridge formations. Therefore, dermatoglyphic patterns becomes a good material for genetic studies, because unlike stature, intelligence, and body weight, they are not significantly influenced by age or by postnatal environmental factors. Each fingerprints is unique and is based on the genetic characteristics of each individual (Abhilash et al. 2012).

In our study, it was observed that both male and female subjects had maximum of loop pattern and the male subjects showed no arch pattern. Similar results were seen in another study where the loop pattern was seen the highest in both gender and no arch pattern was seen in females (Venkatesh et al. 2012).

It was also noted in our study that the subjects with whorl pattern showed high caries incidence similar to the findings in various studies (Abhilash et al. 2012, Madan et al. 2011), were increased occurrence of whorls was noted with higher caries susceptibility. However some studies showed contrast results (Agravat et al. 2014) such as the female subjects with whorl patterns showed no caries and those with loop pattern showed the maximum occurrence of dental caries.

It was found that more than $50 \%$ of the individuals with arch pattern showed no dental caries in our study, in contrast to a previous study were $60 \%$ of individuals with loop pattern were caries free. (Venkatesh et al. 2012).

\section{Conclusion}

It can be concluded that there is a definite correlation between dermatoglyphics and dental caries. Research and studies that have been done to correlate dermatoglyphic patterns and dental caries open a window for predicting dental caries. If an individual is more susceptible to dental caries and identified in early childhood, the clinician can undertake preventive steps. Dermatoglyphics serves to strengthen the diagnostic impression of the disease from an early age and hence preventive oral health measures can be undertaken.

Table 1: Gender- Wise Distribution of the Types of Dermatoglyphics Pattern in Right Thumb

\begin{tabular}{|c|c|c|c|c|}
\hline \multirow{2}{*}{ Gender } & \multicolumn{3}{|c|}{ RIGHT THUMB } & \multirow{2}{*}{ Total } \\
\hline & Loop & Whorl & Arch & \\
\hline \multirow{2}{*}{ Male } & 37 & 32 & 0 & 69 \\
\hline & $53.6 \%$ & $46.4 \%$ & $.0 \%$ & $100.0 \%$ \\
\hline \multirow{2}{*}{ Female } & 71 & 54 & 6 & 131 \\
\hline & $54.2 \%$ & $41.2 \%$ & $4.6 \%$ & $100.0 \%$ \\
\hline
\end{tabular}

Table 2: Gender-Wise Distributions of the Types of Dermatoglyphics Pattern in Left Thumb

\begin{tabular}{lllll}
\hline \multirow{2}{*}{ Gender } & \multicolumn{3}{c}{ LEFT THUMB } & Total \\
& Loop & Whorl & Arch & \\
\hline \multirow{2}{*}{ Male } & 49 & 20 & 0 & 69 \\
& $71.0 \%$ & $29.0 \%$ & $.0 \%$ & $100.0 \%$ \\
\multirow{2}{*}{ Female } & 71 & 53 & 7 & 131 \\
& $54.2 \%$ & $40.5 \%$ & $5.3 \%$ & $100.0 \%$ \\
\hline
\end{tabular}

Table 3: Gender- Wise Distribution of Caries Experience

\begin{tabular}{lllll}
\hline \multirow{2}{*}{ Gender } & No Caries & $1-3$ DMFT & $>3$ DMFT & Total \\
\hline Male & 15 & 38 & 16 & 69 \\
& $21.7 \%$ & $55.1 \%$ & $23.2 \%$ & $100.0 \%$ \\
\multirow{2}{*}{ Female } & 23 & 61 & 47 & 131 \\
& $17.6 \%$ & $46.6 \%$ & $35.9 \%$ & $100.0 \%$ \\
\multirow{2}{*}{ Total } & 38 & 99 & 63 & 200 \\
& $19.0 \%$ & $49.5 \%$ & $31.5 \%$ & $100.0 \%$ \\
\hline
\end{tabular}


Table 4: Percentage Distribution of Association between the Right and Left Thumb Ridge Pattern with Dental Caries Experience

\begin{tabular}{llllll}
\hline \multicolumn{5}{c}{ DMFT categories } & p Value \\
\hline & LOOP & 24 & 52 & 32 & \\
RIGHT & & $22.2 \%$ & $48.1 \%$ & $29.6 \%$ & \\
THUMB & WHORL & 10 & 46 & 30 & \\
& & $11.6 \%$ & $53.5 \%$ & $34.9 \%$ & 0.013 \\
& ARCH & 4 & 1 & 1 & \\
& & $66.7 \%$ & $16.7 \%$ & $16.7 \%$ & \\
& & & & & \\
LEFT & LOOP & 25 & 59 & 36 & \\
THUMB & WHORL & 9 & 39 & $25 \%$ & \\
& & $12.3 \%$ & $53.4 \%$ & $34.2 \%$ & \\
& & 4 & 1 & 2 & \\
& ARCH & $57.1 \%$ & $14.3 \%$ & $28.6 \%$ & \\
\hline
\end{tabular}

\section{References}

[1] Abhilash, PR , Divyashree R, Patil S, Gupta M, Chandrasekar T, Karthikeyan R ( 2012) Dermatoglyphics in Patients with Dental Caries: A Study on 1250 Individuals. J Contemp Dent Pract 13 (3), 266-274. http://dx.doi.org/10.5005/jp-journals-10024-1135.

[2] Prabhu N, Issrani R, Mathur S, Mishra G, Sinha S. (2014) Dermatoglyphics in Health and Diseases-A Review. Journal of Research and Advancement in Dentistry 3 (2), 20-26.

[3] Patil AD, Joshi DS, Patwardhan SA. (2014) Palmar Dermatoglyphics in Abo Blood Groups. International Journal of Recent Trends in Science And Technology 10(2), 396-398

[4] Prabha JL, Thenmozhi R. (2014) A short review of Dermatoglyphics. J Pharm Sci \& Res 6(4), 200-202.

[5] E CD, Ahmed J, Shenoy N, Binnal A. (2013) Dermatoglyphics in Dentistry- A review. IJCRR 5(21), 30-33.

[6] Sharma A, Singh M, Chaudhary S, Bajaj N, Bhalla M, Singh J.(2013) Dermatoglyphic Characterization of Dental Caries and its Correlation to Salivary $\mathrm{Ph}$. An in vivo Study. Indian Journal of

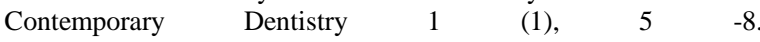
http://dx.doi.org/10.5958/j.2320-5962.1.1.002.

[7] Thakkar VP, Rao A, Rastogi P, Shenoy R, Rajesh G, Pa BHM.(2014) Dermatoglyphics and Dental Caries: A Cross Sectional Study among 12 Year Old School Children in Mangalore, India. Indian Journal of Forensic Medicine and Pathology 7(1), 19-25.

[8] Ramani P, Abhilash PR, Sherlin HJ, Anuja N, Premkumar P, Chandrasekar T et al. (2011) Conventional Dermatoglyphics-Revived Concept: A Review. International Journal of Pharma and Bio Sciences 2(3), 446-458.

[9] Prabhu N, Issrani R, Mathur S, Mishra G, Sinha S. (2014) Dermatoglyphics in Health and Oral Diseases-A Review. JSM Dent 2(4), 1044.

[10] Soben Peter (2009) Indices in Dental Epidemiology. In Essentials of Preventive and Community Dentistry. Arya Medi Publishing House Pvt. Ltd. New Delhi. Pp. 343-346.

[11] Agravat D, Agarwal N, Patel P. (2014) Dermatoglyphics: A Tool for Dental Caries Prediction. J Adv Med Dent Scie Res 2(3), 66-69.

[12] Venkatesh K G, Ravindran DM, Joseph I, Gururanjan A, Balasubramanian. (2012) Existence of dental caries and thumb ridges in a rural school population. International Journal of Integrative sciences, Innovation and Technology 1(5), 50-52.

[13] Madan N, Bajaj N, Rathnam A. (2011) Palmistry: A tool for dental caries prediction! Indian J Dent Res 22 (2), 213-18. http://dx.doi.org/10.4103/0970-9290.84289. 